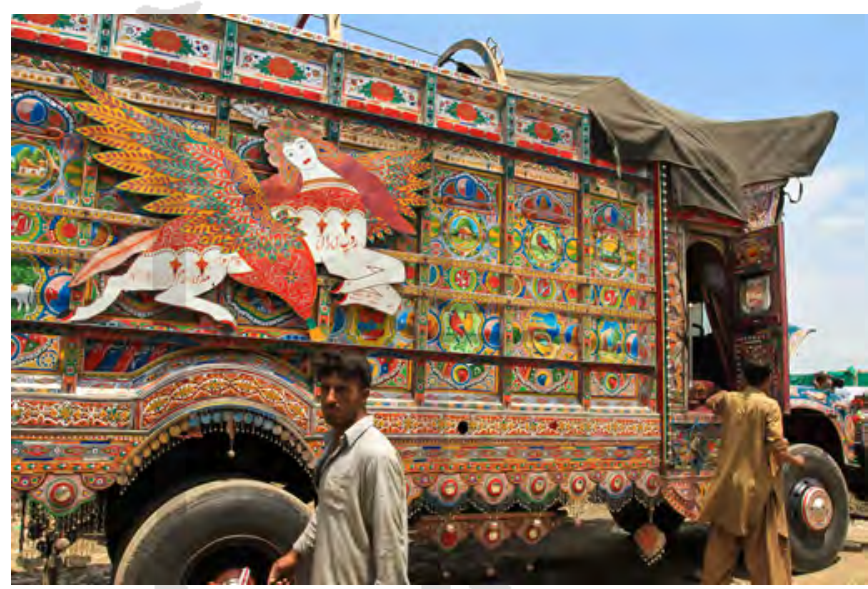

Abb. 1 Beim Bemalen von LKWs, wie es in Pakistan, Afghanistan und in Südostasien üblich ist, finden auch religiöse Motive Berücksichtigung. Diesen LKW nahe Rawalpindi in Pakistan ziert neben vielen anderen Motiven eine großformatige Darstellung des legendären Buraq, auf dem Mohammed seine Nachtreise in den Himmel antrat.

\title{
Einführender Teil
}

Einige grundsätzliche Bemerkungen zur islamischen Ikonographie

Im Vergleich zur klassisch-antiken, zur christlichen oder auch zur hinduistischen Ikonographie ist die islamische Bilderwelt eher als profan zu charakterisieren. Ein Indiz dafür kann darin gesehen werden, dass der Koran, das heilige Buch der Muslime und die den Koran ergänzenden Hadithe nicht illustriert wurden ${ }^{1}$, und für Moscheen und andere dem Gebet oder der religiösen Andacht dienende Räume dies mit wenigen Ausnahmen ebenfalls gilt. Die fast vollständige Vermeidung des Bildes im religiösen Kontext gilt auch angesichts der Tatsache, dass der Islam trotzdem Darstellungen des Propheten Mohammed ebenso kennt wie solche der im Islam anerkannten vorlaufenden Propheten, die nahezu alle mit den Patriarchen und Propheten des biblischen Alten und sogar Neuen Testaments von Adam über Abraham und Mose bis zu Jesus übereinstimmen. Die Herkunft des Islam aus Judentum und Christentum ist unverkennbar. Illustrieren die Bilder im Christentum jedoch die Heilsgeschichte und sind Bilder der Dargestellten zumindest in Teilen verehrungswürdig oder als heilig anzusehen, so verbildlichen sie im Islam keine Heilsgeschichte, sondern nur Geschichte. Erst recht fehlen natürlich Gottesdarstellungen, die im Islam generell durch kalligraphische Schriftzüge ersetzt sind. Von Ausnahmen dieser Bildervermeidung wird an anderer Stelle zu sprechen sein. Sie betreffen vor allem die Zeit nach dem 16. Jahrhundert, als in Persien und Indien unter europäischem Einfluss christliche und islamische Heiligenbilder entstehen. Gravierende Auswirkungen auf das Verhältnis zum Bild im Allgemeinen und zum Heiligenbild im Besonderen hatte die schiitische Volksfrömmigkeit.

Beherrschen also geometrische und florale Dekorationen sowie Kalligraphien den Schmuck religiöser Gebäude, so zeigt sich im profanen Bereich ein völlig anderes Bild. Hier herrschte von Anfang an ein Bilderreichtum, der hinter dem der Umgebungs-

1 Mit dieser Verbindlichkeit brach erst der von den beiden Muslimas Lamya Kaddor und Rabeya Müller herausgegebene und mit Illustrationen von Karl Schlamminger versehene ,Koran für Kinder und Erwachsene', München 2008, der entsprechend in der muslimischen Welt kontrovers beurteilt wird. kulturen nicht zurücksteht. Ist im Bereich monumentaler Bildschöpfungen die Spurensuche zumindest in den ersten Jahrhunderten aufgrund des erhaltenen Materials schwierig, so offenbart vor allem die Buchillustration ein kaum glaubliches Spektrum an Sujets, das hinter anderen Ikonographien nicht zurücksteht. Standen am Anfang der Buchillustration, der seit dem 13. Jahrhundert greifbar ist, zunächst Manuskripte für den praktischen Gebrauch, namentlich medizinische, naturkundliche und wissenschaftliche Werke, deren Bebilderung zur besseren Verständlichkeit einfach sinnvoll ist, so begegnen schon zur selben Zeit poetische Werke, Erzählungen und Fabelgeschichten wie Kalila und Dimna in illustrierten Fassungen. Ältere Werke, die es gegeben haben muss, sind nur in Fragmenten (Abb. 46) oder im Spiegel der Kleinkunst greifbar.

Es ist eine unumstößliche Tatsache, dass der Bilderreichtum im persischen und indischen Islam weitaus umfangreicher ist als im westlichen, und das kann nicht nur eine Frage des erhaltenen Bestandes sein. Zur Erklärung können viele Aspekte herangezogen werden; unverkennbar ist, dass die persischen Dichter und Historiker von Firdausi mit seinem Schahname über Nizamis Khamsa und Raschid ad-Dins Weltgeschichte richtungsweisende ikonographische Impulse gegeben haben. In Persien und Indien erreichte die islamische Malerei ihre Höhepunkte. Der Wechsel zum Schiitentum unter den Safawiden in Persien öffnete schließlich nicht nur die Tore zu einer öffentlichen Monumentalmalerei, sondern sogar zu einer Heiligenikonographie und einer heutzutage populären Bildkunst, die Bilder des Propheten, von Ali und dem Buraq einschließen (Abb. 1). Der östliche und insbesondere der schiitische Islam haben endgültig ihre Scheu vor dem Bild abgelegt.

Aus diesem Vorspruch ergibt sich, dass es die islamische Ikonographie nicht gibt. Sie muss nach Zeitstellung, geographischem bzw. politischem Raum und Bildträger differenziert werden. Vergleicht man sie mit der christlichen Ikonographie, so hat sie eine andere Funktion. Dienen christliche Bilder im kirchlichen wie im privaten Raum der religiösen Andacht, Vergewisserung und Glaubensstärkung und damit zugleich der Festigung des kirchlichen Machterhalts, so dienen Bilder im Islam der Festigung politischer Herrschaften, und im privaten Bereich 


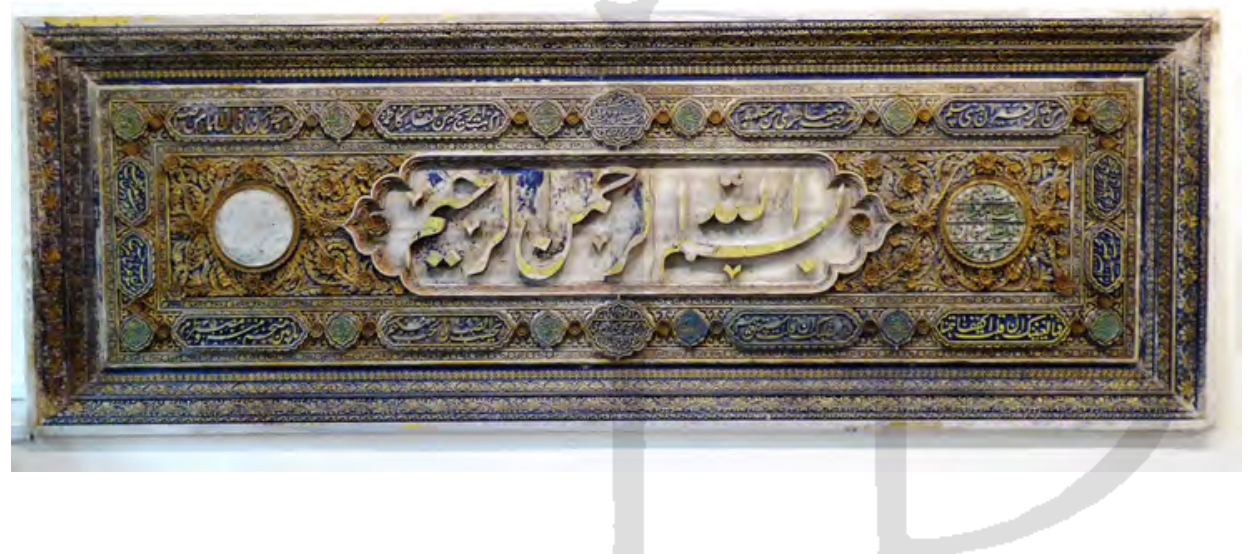

Abb. 2 Kalligraphische Darstellung des Segenswunsches Basmala: Im Namen Allahs, des Allerbarmers, des Barmherzigen. Marmortafel aus Ägypten, 1845. Täbris, Aserbaidschan Museum.

transportieren sie den Wunsch nach Glück, Wohlergehen und durchaus auch persönlicher Frömmigkeit. Vielleicht sind islamische Bilder dann tatsächlich nicht im gewohnten Sinn religiös, spirituell sind auch sie.

Viele Gegenstände der sog. Kleinkunst sind als Geschenke zu verstehen, die unterstützt durch entsprechende Inschriften dem Beschenkten alle erdenklichen Wohltaten wünschen. Häufig enthalten sie den Segenswunsch Basmala (Bismillah), im Namen Gottes, oder den sog. Thronvers (Sure 2, 255): „Allah - kein Gott ist da außer Ihm, Dem Ewiglebenden, Dem durch Sich-Selbst-Seienden. Ihn ergreift weder Schlummer noch Schlaf. Ihm gehört, was in den Himmeln und was auf der Erde ist. Wer ist es, der bei Ihm Fürsprache einlegen könnte außer mit Seiner Erlaubnis? Er weiß, was vor ihnen und was hinter ihnen liegt; sie aber begreifen nichts von Seinem Wissen, es sei denn das, was Er will. Weit reicht Sein Thron über die Himmel und die Erde, und es fällt Ihm nicht schwer, sie (beide) zu bewahren. Und Er ist der Hohe, der Allmächtige." Der Glaube an Allah schließt allerdings nicht aus, dass man sich auch bildlich mit Amulett und Talisman gegen die Unbilden und Gefahren der Welt schützt, Divination betreibt und den Bildern Heil- und Segenskraft zutraut. Und so sind wir letztlich doch bei einer religionsphänomenologisch als religiös zu nennenden Bedeutung angelangt, die Bilder haben können. Doch zugleich ist es die Macht des geschriebenen Wortes, die dieses selbst zum Bild werden lässt (Abb. 2). Manche halten deshalb die Kalligraphie für das eigentliche, das typische Bild des Islam - wenn es dann nicht doch eine Unzahl von bildlichen Darstellungen gäbe, denen dieses Bildwörterbuch zur islamischen Ikonographie gewidmet ist.

\section{Das ,Bilderverbot ${ }^{\star}$}

In einem Buch, das sich mit der islamischen Bilderwelt befasst, müssen eigentlich keine Worte über ein islamisches Bilderverbot verloren werden, das ohnehin vielfach diskutiert wurde. ${ }^{2}$ Nicht nur, dass ein solches im Koran keine Begründung findet, sondern

2 Ignaz Goldziher, Zum islamischen Bilderverbot, in: Zeitschrift der Deutschen Morgenländischen Gesellschaft 74 (1920), S. 288; Rudi Paret, Textbelege zum islamischen Bilderverbot, in: Das Werk des Künstlers. Studien H. Schrade dargebracht, Stuttgart 1960, S. 36-48; Daan van Reenen, The Bilderverbot, a new survey, in: Der Islam. Journal of the History and Culture of the Middle East 67 (1990), S. 27-77; Silvia Naef, Bilder und Bilderverbot im Islam, München 2007; Reiner Sörries, Handbuch zur Islamischen Archäologie und Kunstgeschichte, Wiesbaden 2018, S. 283ff.passim; Finbarr B. Flood, Islam and Image: Polemics, Theology and Modernity, London in Vorbereitung. allenfalls aus einigen Hadithen und der geschichtlich bedingten Fortentwicklung der islamischen Theologie zu erschließen wäre, sondern die islamische Kunst tritt selbst den Beweis an, dass man Bilder gebraucht und geschätzt hat. Man kann sogar sagen, dass sowohl die Zahl der Motive wie der bildtragenden Objekte unermesslich ist. Freilich ist dabei zu berücksichtigen, dass islamische Bildkunst vorrangig Buchkunst ist, aber keineswegs ausschließlich. Von der sog. Kleinkunst bis zur Wandmalerei sind praktisch alle Kunstgattungen vertreten. Außerdem sind zwei wichtige Faktoren zu nennen: (1) der frühe Islam entwickelte seine Bildwelt aus der umgebenden hellenistisch-byzantinischen sowie der sassanidischen Umgebungskultur. Man ging zumindest im profanen Bereich recht unbefangen mit den Bildern um. (2) Der ,mittelalterliche' Islam wurde hinsichtlich seines Bildgebrauchs durch die Seldschuken geprägt, die ihrerseits das Kunstschaffen in Persien bestimmt haben. Im ganzen Osten, so Mehr Ali Newid, habe man das malerische Erbe der altiranischen Kultur nie aufgegeben. Trotz eines geringen Denkmälerbestandes ließe sich das schon für die Zeit der Samaniden (873-999) ebenso sagen wie für die Epoche der Gaznawiden (994-1040), aus der es konkrete Hinweise auf Wandmalereien in königlichen Palästen gibt. Ebenso seien die Paläste der Timuriden mit wichtigen Episoden ihrer Geschichte und Eroberungszüge sowie mit Portraits der Herrscherfamilie ausgemalt gewesen. ${ }^{3}$ Auch Ernst Grube ging bei seiner Besprechung der Wandmalereien des 17. Jahrhunderts in Isfahan von einem seit den Umayyaden nie unterbrochenen Traditionsstrang aus. ${ }^{4}$

Manche vergleichen die dominierende Rolle Persiens in der islamischen Kunst mit der Rolle, die Italien für die abendländische Kunst gespielt hat. Eine weitere Blüte erlebte die islamische Bildkunst in Indien, die einerseits zunächst durch Persien vorgegeben war und andererseits durch europäische Kontakte einen weiteren Schub erfuhr. Ähnliches gilt für die osmanische Kunst. Seit dem 16. Jahrhundert scheinen alle (theologischen) Dämme gegen die Bilder ohnehin gebrochen zu sein, die lediglich die Moscheen (weitgehend) vor dem Einzug von figürlichen Darstellungen bewahren konnten. Aus den islamischen Gebetshäusern blieb das Bild tatsächlich von floralen Motiven abgesehen verbannt. Landschaften und Architekturvignetten erreichten die Moscheedekoration allerdings doch seit dem 18. Jahrhundert. Seit dem 19. Jahrhundert führten die Kontakte mit Europa zu-

3 Newid (2006), S. $78 f$

4 Ernst Grube, Wall Paintings in the Seventeenth Century Monuments of Isfahan, in: Iranian Studies Vol. 7, No. 3/4, Studies on Isfahan: Proceedings of the Isfahan Colloquium, Part II (Summer - Autumn, 1974), S. 511-542. 
mal in Persien und in der Türkei zu eigenen Kunst- und Malschulen mit Künstlern, deren Bilder sogar im Abendland Aufmerksamkeit fanden. Man wird abschließend zu diesem Thema allerdings einen großen Unterschied zwischen dem asiatischen und dem mediterranen bzw. zwischen dem persischen und dem arabischen Islam konstatieren. Bilder und zumal figürliche Bilder waren und blieben eine Domäne des asiatisch-persischen Islam, während der mediterran-arabische Islam sich größerer Zurückhaltung befleißigte. Nicht umsonst erstarkte hier der bilderfeindliche und bildzerstörerische Wahhabismus.

\section{Persien und der schiitische Islam als Katalysatoren islamischer Ikonographie}

Wer heutzutage durch den Iran reist, sieht sich bereits im öffentlichen Raum mit einer Fülle von Bildern und figürlichen Darstellungen konfrontiert. Konterfeis der religiösen Führer begegnen allerorts, und die Portraits der im Irankrieg gefallenen Märtyrer säumen die Straßen in den großen und kleinen Städten. In den Basaren werden Bildteppiche und gerahmte Motive von idyllischen Landschaften und europäischen Ballszenen ebenso angeboten wie Bilder des Propheten und seines Schwiegersohnes Ali. Diese hängen auch in den Cafés und anderen öffentlichen Orten. Man wundert sich und denkt, dass das islamische Bilderverbot hier nicht gilt. Keine Scheu vor den Portraits kennt man auf den Friedhöfen an den Gräbern der bereits genannten Märtyrer. Es sind die reinsten Bildergalerien. Selbst Hochhausfassaden sind mit überdimensionalen Wandgemälden versehen. Es scheint so zu sein, als würden schiitische Autoritäten das Bilderverbot weit weniger rigoros vertreten als sunnitische Theologen.

Mögen das auch durchaus neuzeitliche Erscheinungen sein, so hat diese Bilderfreundlichkeit in Persien doch Tradition. Und dies hat etwas mit Persien zu tun und dem dort seit dem 16. Jahrhundert vorherrschenden Schiismus. Persien war im Gegensatz zum arabischen Orient immer vom Osten beeinflusst, der Bilder und Symbole in das islamische Persien eintrug. Im Rückgriff auf die alte Größe Persiens hat man sich immer vom arabischen Islam distanziert und seine eigene Kultur gepflegt, wo nach dem Mongolensturm die Timuriden eine spezifisch islamische Ikonographie geschaffen hatten. Glanzvolle Zeugnisse sind die Miniaturen in den illustrierten Manuskripten, die den Großteil islamischer Ikonographie bereithalten. Und mit dem Übertritt zur schiitischen Konfession unter den Safawiden hat sich diese Tendenz noch verstärkt.

Einen enormen Schub erhielt die schiitische Ikonographie durch die Popularisierung der Erinnerung an den Protomärtyrer Hussein, der mit seinen Getreuen verraten wurde und in der Schlacht von Kerbela 680 das Martyrium erlitt. Zur alljährlichen Feier des Aschura-Festes (Ta'ziya) wurde auf öffentlichen Plätzen vor der Kulisse riesiger Schlachtengemälde (Pardeh) die Passion Husseins erzählt und nachgespielt. Die ursprünglich temporären Bildwerke auf Leinwand erfuhren in den eigens errichteten, Tekyeh oder Hussainia genannten Festspielhäusern ihre Fixierung an permanenten Orten. Wann dies genau geschah ist nicht exakt feststellbar, doch lässt sich ihr Stil im Sinne der sog. Kaffeehausmalerei seit den Gemälden im Tschehel Sotun Palast in Isfahan in der Mitte des 17. Jahrhunderts nachweisen. Die erhaltenen Beispiele in den Tekyeh stammen indes erst aus dem 19. und frühen 20. Jahrhundert. In ihnen wurden vorzugsweise die tragischen Ereignisse der Schlacht von Kerbela in Gemälden und
Fliesenbildern dargestellt. Ein weiterer Ort für Bilderzyklen dieser Art waren die Mausoleen der Imame und ihrer Nachfahren, die Imamzade genannt werden. Und den gleichen Namen besitzen diese Mausoleen. Aus diesen Bilderzyklen emanzipierten sich die Portraits der wichtigsten Protagonisten wie 'Alī ibn Abī Tālib und dessen Söhnen Hasan und Hussein sowie von Mohammed und Fatima, welche die islamische heilige Familie bilden. Ihre Konterfeis nahmen den Charakter von Heiligenbildern an, zu denen sich schließlich Abbas ibn Ali gesellte, der Halbbruder und Bannerträger Husseins.

Das ikonographische Spektrum blieb indes nicht auf den Themenkreis von Kerbela und seine Protagonisten beschränkt, sondern wurde um zahlreiche andere Themen erweitert. Herausragendes Beispiel ist die in kadscharischer Zeit errichtete Tekyeh Moaven al-Molk in Kermanshah, deren Bilderreichtum der gesamten persischen Geschichte und ihren Herrschern gewidmet ist. Das Bild des gerechten Herrschers Suleiman (Salomo) und die im Islam beliebte Geschichte des biblischen Yusuf (Joseph) bilden hier eigene Schwerpunkte. Der wenig beachtete Anteil der jüngeren schiitischen Bildtradition wurde von Mehr Ali Newid erstmals umfassend gewürdigt. ${ }^{5}$

\section{Die kulturellen und literarischen Quellen der islamischen Ikonographie}

Das ikonographische Spektrum der islamischen Kunst umfasst alle Bereiche der natürlichen und der übernatürlichen Welt. Als Quellen der Bilder sind zunächst die ikonographischen Traditionen der Umgebungskulturen von Byzantinern, Juden, Sassaniden, Sogdiern, Hindus oder Chinesen zu nennen. Themen lieferten der Koran, der selbst nie illustriert wurde, und die islamische Überlieferung, deren Inhalte in Teilen mit dem jüdisch-christlichen Alten Testament und vereinzelt mit dem christlichen Neuen Testament übereinstimmen. Weitere Impulse erhielt die Ikonographie durch historische, mythologische und poetische Werke vor allem persischer Schriftsteller wie bspw. Firdausī (940-1020 u. Z.) oder Nizami (1141-1209 u. Z.). Ihre Werke wurden seit dem 13. Jahrhundert in immer neuen Ausgaben kopiert und illustriert. Schließlich lieferten die je eigene Geschichte und Gegenwart genügend Stoff für Illustrationen, darunter die berühmten Biographien der Mogulherrscher Babur und Akbar. Lebendige Beschreibungen und Illustrationen des Alltags und der Festkultur sind u. a. den Osmanen zu verdanken. Nicht zu vernachlässigen ist, dass auch das christliche Abendland, Europa, für den Islam eine Umgebungskultur ist, deren Einfluss sich vor allem seit dem 16. Jahrhundert stetig steigerte. Dies soll im Folgenden etwas systematisiert werden. Die wichtigsten literarischen Quellen werden, soweit sie illustriert wurden, auch im lexikalischen Teil genannt.

\section{Bildliche Traditionen der Umgebungskulturen}

Nach dem Aufbruch aus Arabien stieß der Islam in Palästina und Syrien zunächst auf das christliche Byzantinische Reich, das seinerseits zutiefst hellenistisch geprägt war. Byzanz verstand sich als Römisches Reich und hatte römische Traditionen unter

5 Newid (2006) sowie etwas später Ingvild Flaskerud, Visualizing Belief and Piety in Iranian Shiism, London 2010. 

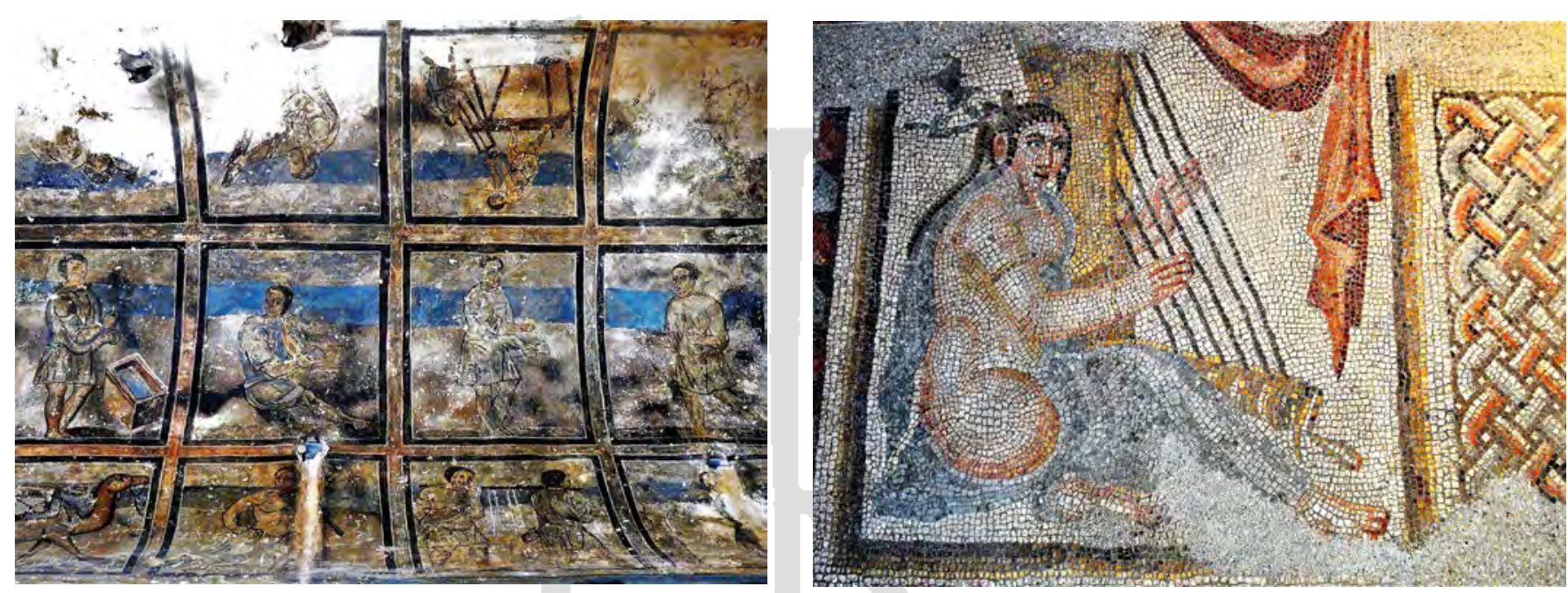

Abb. 3 Die Deckenfresken im Gewölbe zwischen Thronsaal und Bad im umayyadischen Wüstenschloss von Qusair Amra (Jordanien) schildern Alltagsszenen wie handwerkliche Arbeiten und Karawanen, die aus einem römisch-byzantinischen Bildkatalog zu stammen scheinen. Abb. 4 Mosaik aus dem Palast von Bishapur, um 260 u. Z. Die Harfenspielerin gehörte in diesem sassanidischen Palast wie später in der islamischen Bildsprache zum höfischen Repertoire. Paris, Louvre.

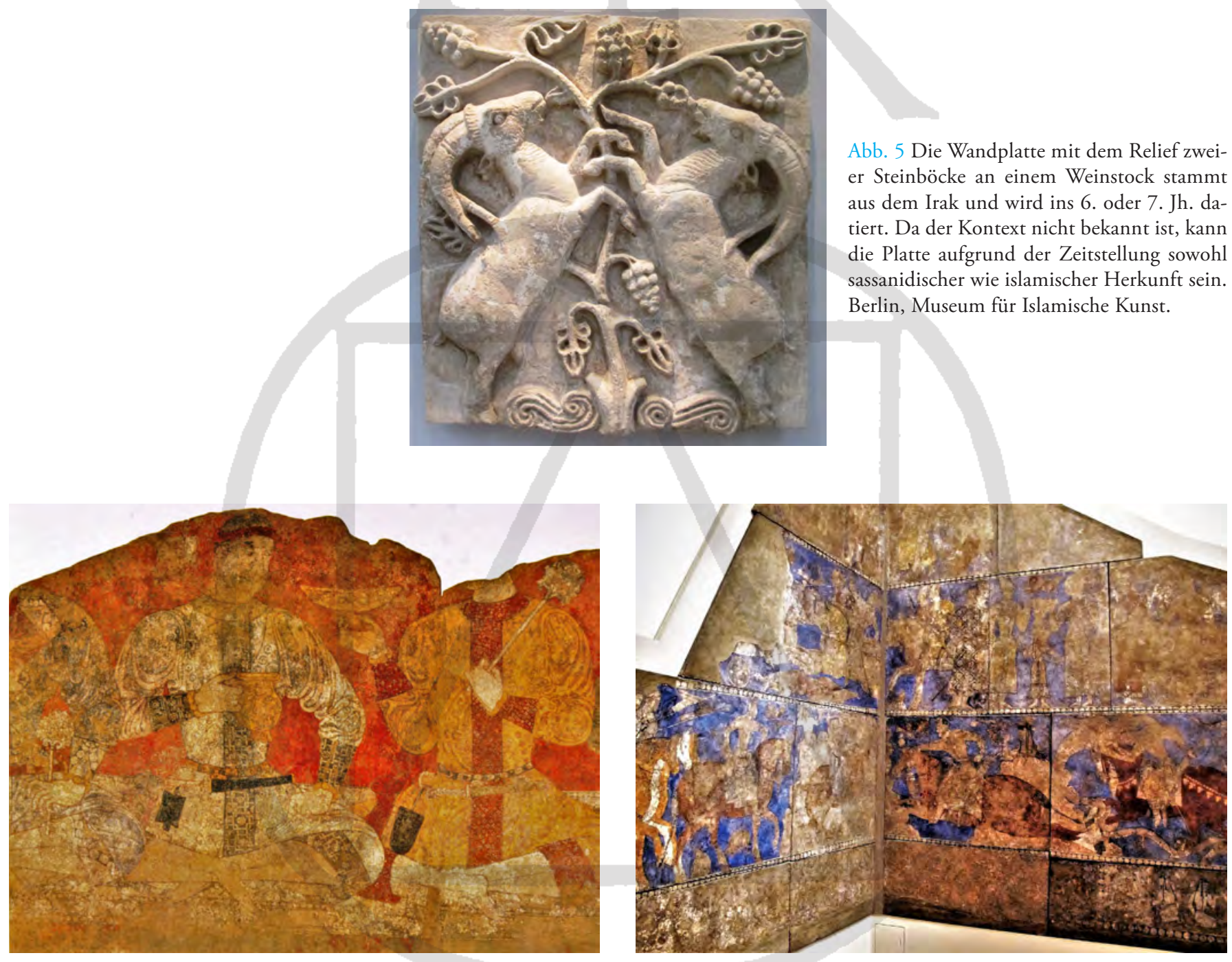

Abb. 6 Der Ausschnitt aus einer sogdischen Wandmalerei in Pandschakent (Tadschikistan) zeigt einen Herrscher im Lotussitz, der in seiner rechten Hand einen Krug hält, während ihm zur Linken ein Mundschenk eine Schale reicht. 7./8. Jh. Solche Bankettszenen gehören auch zum Standardrepertoire der islamischen höfischen Ikonographie. Abb. 7 Im sog. Zeremoniensaal von Pandschakent (Tadschikistan) schildern Wandmalereien die sieben Arbeiten des persischen Nationalhelden Rustam. Diese sogdischen Malereien, um 740 u. Z., sind die ältesten Bildzeugnisse dieses persischen Epos, das im Schahname einen breiten Raum einnimmt und eines der verbreitetsten Bilderzählungen islamischer Bildkunst darstellt. St. Petersburg, Hermitage. 
christlichen Vorzeichen fortgeführt. Architekten und Handwerker aus Byzanz wurden zum Bau der ersten islamischen Großbauten in Jerusalem und Damaskus herangezogen, sodass der Felsendom und die Umayyadenmoschee byzantinisch wirken. Ebenso atmen die sog. Wüstenschlösser in Bauweise und Ausstattung römischbyzantinischen Geist, weshalb mit guten Argumenten die umayyadische Kunst noch der Spätantike zugerechnet wird. Die Fresken in Qusair Amra oder die Bodenmosaiken in verschiedenen Wüstenschlössern könnte man für römisch halten. Sinnfällig wird dies an der Darstellung der Gaia, der göttlichen Personifikation der Erde, in Qasr al-Heir al-Gharbi, die flankiert von Kentauren und einer rahmenden Weinranke für Wohlstand und Überfluss steht (Abb. 140). Aus al-Fudayn stammt ein Kohle- oder Weihrauchbecken mit dionysischen Szenen, das noch ebenso gut in die antike Zeit passen würden (Abb. 111). Nicht weniger römisch sind die Malereien in Qusair Amra, die u.a. Szenen aus dem Alltag enthalten (Abb. 3).

Was für Syrien und Palästina gilt, kann entsprechend in Ägypten gesehen werden. Haben sich hier vor allem Stoffe aus der frühislamischen Epoche erhalten, so lassen sich hier christliche oder islamische Arbeiten kaum voneinander unterscheiden; sie sind eben koptisch bzw. ägyptisch-spätantik (Abb. 227a). Blickt man auf die weitere Entwicklung, so bleiben zwar manche hellenistische Elemente vor allem aus Wissenschaft (Abb. 112a) und Philosophie bewahrt (Abb. 305), und vor allem der antike Alexanderroman hat stark nachgewirkt (Abb. 187a+b), doch wird man konstatieren, dass zumal die hellenistisch-byzantinische Ikonographie nicht denselben nachhaltigen Einfluss auf die islamische Bilderwelt ausübte wie die im Folgenden zu skizzierende sassanidische Welt.

Hat im Nahen Osten und im Mittelmeerraum die hellenistisch-byzantinische Kultur ihren Einfluss auf die Entwicklung der islamischen Kunst und Ikonographie genommen, so zeigt sich der östliche und asiatische Islam als Erbe der Sassaniden, deren prunkvolle Hofhaltung sie ebenso übernommen haben wie große Teile der persischen Mythologie und der zoroastrischen Religion. Vielfach wird deshalb das Gebiet des heutigen Iran und seiner Nachbarländer als Katalysator der islamischen Kultur angesehen. Übernommen wurden die fürstlichen Symbole wie etwa der Becher ebenso wie die höfischen Lustbarkeiten, die keineswegs nur Ausdruck von Festgestaltung und Unterhaltung waren, sondern Privilegien und Ausweis der legitimen Herrschaft. So sind etwa die Szenen von Musikantinnen in den Mosaiken von Bishapur, der Stadt des Schapur, nicht einfach Dekoration, sondern Herrschaftssymbole (Abb. 4). Solchen Musikanten wie Tänzern, Becherhaltern und Trinkenden wird man in der islamischen Ikonographie auf Schritt und Tritt begegnen. Die persische Mythologie brachte historische wie legendäre Elemente mit sich einschließlich der ganzen Welt der Fabelwesen, die in illustrierten Manuskripten und auf den Gegenständen der Kleinkunst ihren Niederschlag fanden. Die Nähe zur sassanidischen Kunst ist so groß, dass sich kontextlose Objekte weder der sassanidischen noch der frühislamischen Kunst eindeutig zuweisen lassen. Dies mag eine Wandreliefplatte mit antithetisch an einem Weinstock angeordneten Steinböcken verdeutlichen, die aus dem Irak stammt und ins 6./7. Jahrhundert u. Z. datiert wird (Abb. 5). Sowohl die Ikonographie mit Steinbock und Weinrebe kommt in der islamischen Kunst vor, als auch die konsequente Symmetrie als ein Wesenselement islamischer Kunst gelten kann. Gleich- wohl kann das Stuckrelief noch sassanidisch sein. Dabei muss berücksichtigt werden, dass die Sassaniden ihrerseits die Erben der Achämeniden waren und deren Vorstellungen weiter vermittelten. Fast wörtlich wurde deshalb in der islamischen Kunst des Ostens die Ikonographie von Persepolis übernommen, nicht nur in der Frühzeit und im Mittelalter, sondern durchgehend und dezidiert von den Kadscharen und den Pahlevis, die einen regelrechten neo-achämenidischen Stil kreierten.

Mit der Ausbreitung des Islam nach Zentralasien kamen die Eroberer auch mit Sogdien in Berührung, das sie bis $722 \mathrm{u}$. Z. unterworfen hatten. Dort fanden sie u. a. in Afrasiab (Usbekistan) und Pandschakent (auch Penjikent; Tadschikistan) Häuser, Paläste und Tempel vor, die mit Wandmalereien versehen waren. Neben den Darstellungen in Afrasiab mit Empfängen, Prozessionen und Tierjagden bieten vor allem die Wandmalereien in Pandschakent große Teile des späteren islamischen Bilderspektrums, darunter den Herrscher mit dem Krug (Abb. 6), eine Harfenspielerin, Tanzende und somit Elemente der höfischen Szenerie. Ebenso begegnen Dämonen und Fabelgeschichten. Besonders auffallend sind die Darstellungen des persischen Nationalhelden Rostam/Rustam (Abb. 7), der mit der Dichtung von Firdausis Schahname zu einer zentralen Figur persisch-islamischer Ikonographie wurde. Werden diese Malereien ins 7. und 8. Jahrhundert und damit in Teilen bereits in islamische Zeit datiert, so dokumentieren sie in ihrer Gesamtheit eine präislamische Ikonographie, welche die islamische Bilderwelt befruchtet haben wird. Zudem befanden sich im Fundmaterial zahlreiche Kleinplastiken, darunter ebenfalls höfische Figuren wie unbekleidete Tänzerinnen. Diese künstlerischen, figürlichen Traditionen wurden zumindest zum Teil im islamischen Erbe bewahrt. ${ }^{6}$ Sogdien war in Gänze ein multikultureller und multireligiöser Schmelztiegel, in dem die Muslime ebenso auf Spuren der sassanidischen wie der manichäischen Kunst stießen, wie bereits Thomas Walker Arnold in den 1920 er Jahren festgestellt hatte. ${ }^{7}$ Neuerlich hatte Oleg Grabar diese interkulturelle Gemengelage im Mittleren Osten als Keimzelle der islamischen Kultur herausgestellt. ${ }^{8}$

Mit der Gründung Bagdads 762 u. Z. als neuer Hauptstadt der Abbasiden und der so erfolgten Verlagerung des politischen Schwerpunktes in den Osten, nach Zentralasien, wurde Persien zum Kernland der islamischen Kultur. Vor allem architektonische Vorbilder wurden adaptiert. Über die persische, vorislamische Bildkultur ist hingegen von den achämenidischen und sassanidischen Reliefs abgesehen wenig bekannt, vor allem die Wandmalerei ist fast völlig verloren. ${ }^{9}$ Man kann jedoch auch auf die Malereien in den Buddha-Höhlen von Kizil verweisen, an denen wohl persische Maler beteiligt waren (Abb. 8). Ihr Stil findet sich in den späteren islamischen Miniaturen wieder. Tanzende und musizierende Menschen erscheinen wie die Vorlagen für

6 Guitty Azarpay, Sogdian Painting: The Pictorial Epic in Oriental Art, Berkeley, Los Angeles, London 1981, insb. Continuity of Tradition. The Sogdian Artistic Heritage in Muslim Painting, ebd. S. 170-180.

7 Thomas W. Arnold, Survivals of Sasanian \& Manichaean Art in Persian Painting, Oxford 1924.

8 Oleg Grabar, The Many Facets of Middle Eastern Art, in: Kenneth G. Holum und Hayim Lapin, Hrsg., Shaping the Middle East. Jews, Christians and Muslims in an Age of Transition 400-800 C.E., Bethesda, Maryland 2011, S. 241-255.

9 Vgl. zu dem wenigen Erhaltenen: Maria Vittoria Fontana, Artikel: Art in Iran XII. Iranian Pre-Islamic Elements in Islamic Art, in: Encyclopaedia Iranica, 1986. 


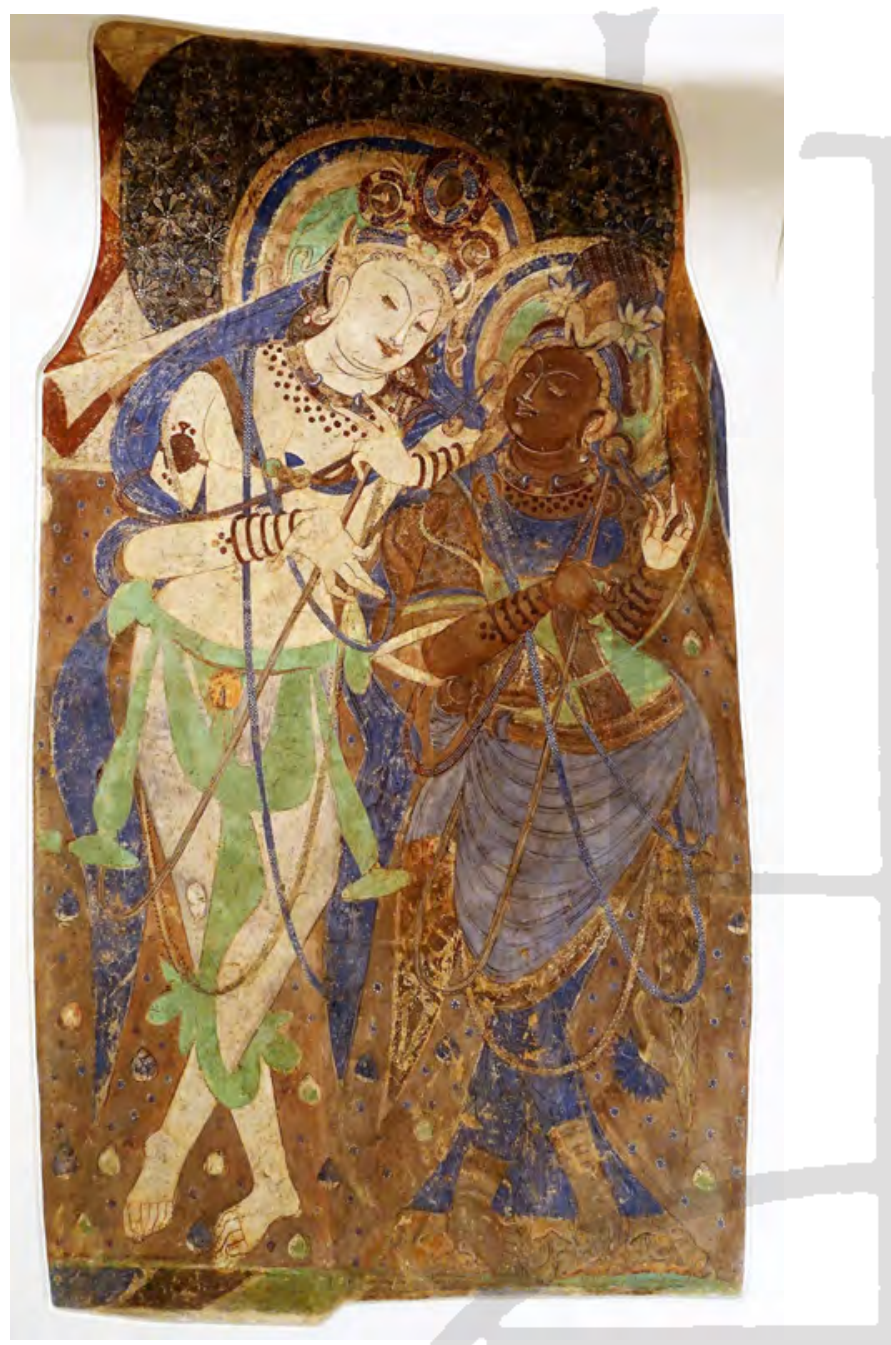

Abb. 8 Diese Wandmalerei aus den Buddha-Höhlen von Kizil (Höhle 171), 2. Viertel 5. Jh., an der nördlichen Seidenstraße in Nordwestchina zeigt einen Tänzer (Gott?) und eine Musikantin, die wie Vorlagen späterer islamischer Miniaturmalerei wirken. Berlin, Ethnographisches Museum.

spätere islamische Sujets. Viele ikonographische Themen aus der Mythologie und der Welt der Fabelwesen haben ihren Ursprung in der vorislamischen Kultur Persiens. Sie wurde nicht zuletzt durch das Schahname Epos des Firdausi für die islamische Kunst Persiens bewahrt. ${ }^{10}$

Angesichts der vorislamischen Kulturen muss man konstatieren, dass die Ausstattung der Paläste und Residenzen mit bildlichem Schmuck in islamischer Zeit ungebrochen fortgesetzt wurde. Das trifft wohl trotz eines teilweise sehr fragmentierten Bestandes zu. Die illustrierten Manuskripte und die Werke der Kleinkunst sprechen eine deutlichere Sprache. Allerdings wird man ebenso festhalten, dass die Moschee als islamisches Gebetshaus zu kaum einer Zeit der bildlichen Ausstattung von Tempeln oder Kirchen nacheiferte.

Der Islam hatte früh auf dem indischen Subkontinent Fuß gefasst, zunächst Diasporagemeinden gebildet, dann aber auch eigene, mächtige Reiche. Diese wiederum waren stark von Persi- en geprägt, konnten indes ihre Begegnung mit Hinduismus und Buddhismus nicht leugnen. Unweigerlich sind Einflüsse dieser Religionen und der indischen Kunst auf den Islam zu beobachten. Kontakte mit Europa hatten weitere Neuerungen zur Folge, die ebenso in der jüngeren osmanischen Kunst zu verzeichnen sind.

\section{Quellen der Ikonographie}

Will man in der islamischen Kultur bei aller Problematik religiöse und profane Sujets unterscheiden, so wird man feststellen, dass in der zeitlichen Abfolge die profanen Motive vor den religiösen rangieren. Die Motive zur Ausstattung von Palästen schöpfte man schon in umayyadischer Zeit aus der hellenistisch-byzantinischen und der sassanidischen Umgebung mit Motiven aus dem höfischen Leben. Dies blieb für fürstliche Residenzen das vorherrschende Thema, das sich zudem in der Kleinkunst der höfischen Eliten niederschlug. Später traten Bilder mit historischen Begebenheiten hinzu, wie es exemplarisch im Tschehel Sotun Palast in Isfahan zu studieren ist. Dort sind die Historienbilder mit den beliebten Genreszenen kombiniert, die mitunter poetischen Werken entlehnt sind. Historisch sind eigentlich auch die zyklischen Darstellungen der Tragödie von Kerbela, die in der schiitischen Welt seit dem 17./18. Jahrhundert in den Imamzade genannten Mausoleen und den Tekyeh genannten Festspielhäusern zu finden sind. Jedoch haben sie einen stark religiösen Charakter, denn sie stellen die Heiligen und Märtyrer der Schiiten dar.

Seit dem 12./13. Jahrhundert hat die Buchillustration die ikonographische Führerschaft übernommen, wobei wieder die profanen Themen den religiösen vorausgehen. Ihre Quellen sind die klassisch-antike Überlieferung, die (vor allem persische) Mythologie und Historie, der Koran und die Hadithe und zuletzt europäische Vorbilder. Dem erhaltenen Bestand zufolge wurden zuerst naturkundliche und medizinische Handschriften illustriert, ehe auch poetische Texte, Geschichten und Fabeln illustriert wurden. Dann treten in rascher Folge nebeneinander historische und religiöse Illustrationen auf, mit denen die mythische Vorzeit (Schahname), die Erzählungen der islamischen Propheten von Adam bis auf Mohammed (Qisas al-anbiyā - Prophetengeschichten), das Leben Mohammeds (Siyer-i Nebi) und schließlich die Geschichte(n) der herrschenden Dynastien und ihrer Fürsten ins Bild gesetzt werden. Besonders auffällig ist, dass die historischen Begebenheiten der natürlichen Welt zunehmend mit Motiven aus der übernatürlichen Welt vermischt werden. Sagenhaftes, Mythologisches und Mysteriöses bilden einen Kernbestand islamischer Ikonographie. Charakteristisch dafür ist das Kitab al-Bulhan (Buch der Wunder). Der beobachtbare Alltag der Muslime findet sich zunächst nur eher zufällig in den historischen Illustrationen, ehe er auch zu einem selbständigen Sujet wurde. Bildentwürfe dieser Vielfalt haben dann aus der Miniaturmalerei wieder in andere Kunstgattungen ausgestrahlt.

Die ikonographische Vielfalt der Kleinkunst ist immens. Ihre Deutung kann jeweils nur aus dem konkreten Objekt abgeleitet werden. Mögen dem Anschein nach die meisten Motive als dekorativ bzw. profan einzustufen sein, so begegnen auch immer wieder religiöse Motive bzw. Bildnisse ihrer religiösen Repräsentanten.

10 Vgl. dazu: Eleanor G. Sims, Boris I. Marshak und Ernst J. Grube, Peerless Images: Persian Figural Painting and Its Sources, Yale 2002. 

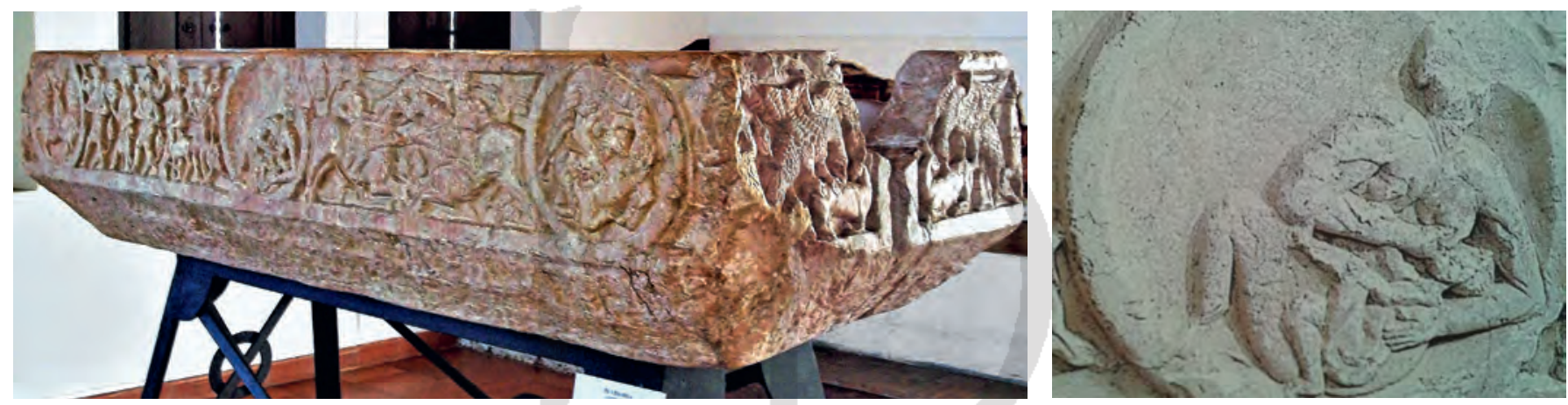

Abb. 9a Zu den selten erhaltenen figürlichen Reliefs aus dem islamischen Andalusien gehört das sog. Xativa Bassin mit Szenen aus dem höfischen Figurenkreis. Darauf sind im Relief Szenen zu sehen, die dem höfischen Leben zuzurechnen sind; Lautenspieler, Trinkende im Garten, Diener, Ringer und Musikanten, ebenso Menschen in einer Art Prozession, die Tiere und Früchte bringen, außerdem verschiedene Tiere und Tierkämpfe. Gefunden in Xativa (Jativa, Spanien), 11. Jh. Xativa, Museo del Almudín. Abb. 9b Ein besonderes Detail auf dem sog. Jativa (Xativa) Bassin ist eine stillende Mutter mit ihrem Kind.

\section{Chronologie und Lokalisierung der islamischen Bilderwelt}

Die islamische Ikonographie bildet keine Einheit, sondern hat zeitlich und geographisch ihre je eigene Ausprägung erfahren.

\section{Antikes Erbe in frühislamischer Zeit (Umayyaden und Abbasiden)}

Unverkennbar ist das Erbe der klassischen Antike und der sassanidischen Kultur. Manche Mosaiken und Malereien in umayyadischen Bauten lassen sich kaum von ihren antiken oder byzantinischen Vorbildern unterscheiden. Bei der berühmten Mschatta-Fassade wurde lange eine sassanidische Herkunft angenommen. Eine eigene islamische Bilderkultur hatte sich noch nicht herausgebildet. Lediglich bei religiösen Bauwerken ist eine anikonische Tedenz bereits feststellbar. Kunst und Kultur der abbasidischen Residenz Samarra lassen ebenfalls die Einflüsse der antiken höfischen Kultur erkennen. Vorgefundene Werke der Malerei und Plastik sind sämtlich einem höfischen Themenkreis verpflichtet. Somit lassen die frühen islamischen Perioden keine grundsätzliche Bildabstinenz erkennen, die allerdings für religiöse Bauten gilt. Diese Feststellungen sind jedoch vorsichtig zu beurteilen, weil für die Frühzeit des Islam von hohen Verlusten an Kunst und Denkmälern ausgegangen werden muss.

\section{Die Entwicklung im Maghreb und in Andalusien (Spanische Umayyaden bis Nasriden)}

Eine Beurteilung der Akzeptanz und Verbreitung figürlicher und szenischer Darstellungen in den Gebieten des westlichen Islam im nordafrikanischen Maghreb und in Spanien fällt nicht leicht. Einerseits muss konstatiert werden, dass es in diesem Großraum weit weniger figürliche Bildwerke gibt als im Islam in den Gebieten östlich von Ägypten. Eine generelle Bildabstinenz kann daraus aber nicht abgeleitet werden, denn es fehlt nicht an herausragenden Exponaten, die Tiere, Menschen und szenische Darstellungen zeigen. Beginnt die Blütezeit in Andalusien mit einem Seitenzweig der Umayyadendynastie, der das Emirat und spätere Kalifat von Cordoba begründete, so sind zunächst in bester spätantiker Tradition eine Reihe von Elfenbeinarbeiten mit figürlichen Darstellungen zu nennen. Unter ihnen ragt zweifellos die 968 u. Z. datierte Pyxis des Prinzen al-Mughira hervor, die sich heute im Louvre in Paris befindet ( $\rightarrow$ Abb. 382). Sowohl der zylindrische Körper wie der Deckel sind mit Szenen geschmückt, die dem höfischen Leben zuzuordnen sind. Weitere Stücke könnten genannt werden. ${ }^{11}$ Die Bronzeplastik ist herausragend mit den sog. Pisaner Greif ${ }^{12}$ vertreten, und auch in der Keramik fehlen figürliche Darstellungen nicht. Gleichwohl wird man feststellen, dass die Mehrzahl der sog. Alhambra-Vasen, die als Glanzstücke andalusischer Keramik gelten, rein kalligraphisch geschmückt sind, während nur eine von ihnen zwischen arabeskenhaftem Blütendekor zwei Gazellen zeigt. ${ }^{13}$ Tatsächlich überwiegen - im erhaltenen Bestand - in Andalusien die anikonischen Werke deutlich, und die Miniaturmalerei müsste man gänzlich ausklammern, wäre da nicht das wunderbar und lebensnah kolorierte Manuskript von Bayad und Riyad ( $\rightarrow$ Abb. 89), welches der almohadischen Zeit im 13. Jahrhundert zugerechnet wird. ${ }^{14}$ Man kann hier nicht von einem isolierten Unikat sprechen, es muss weitere illustrierte Bücher gegeben haben, die nicht erhalten sind.

Ein ebensolches Unikat scheint das unter dem Namen Xativa Bassin, Jativa Bassin oder Pila de Jativa bekannte Becken mir Reliefschmuck zu sein, das in die Taifa-Zeit des 11. Jahrhunderts datiert wird. Es erinnert durchaus an römische oder frühchristliche Sarkophage. Die Szenen zeigen das Leben des Adels zur Zeit der Taifas. Es gibt insgesamt siebenundzwanzig Figuren, darunter einen Lautenspieler, eine im Garten trinkende Figur, Ringer und Männer, die Tiere abwehren. Neben diesen Szenen des Hofes (Abb. 9a) überrascht die singuläre Darstellung einer stillenden Frau (Abb. 9b). Nicht minder isoliert scheint ein Figuren-

11 Vgl. dazu: Jerrilynn D. Dodds, Hrsg., Al-Andalus: The Art of Islamic Spain, Ausstellungskatalog New York Metropolitan Museum of Art, 1992, Kat. Nr. 4, 5 und 7.

12 Ebd. Kat. Nr. 15.

13 Ebd. Kat. Nr. 112

14 Ebd. Kat. Nr. 82; Eva Baer, The ,Pila' of Jativa. A Document of Secular Urban Art in Western Islam, in: Kunst des Orients, Vol. 7, H. 2 (1970/71), S. $142-166$ 

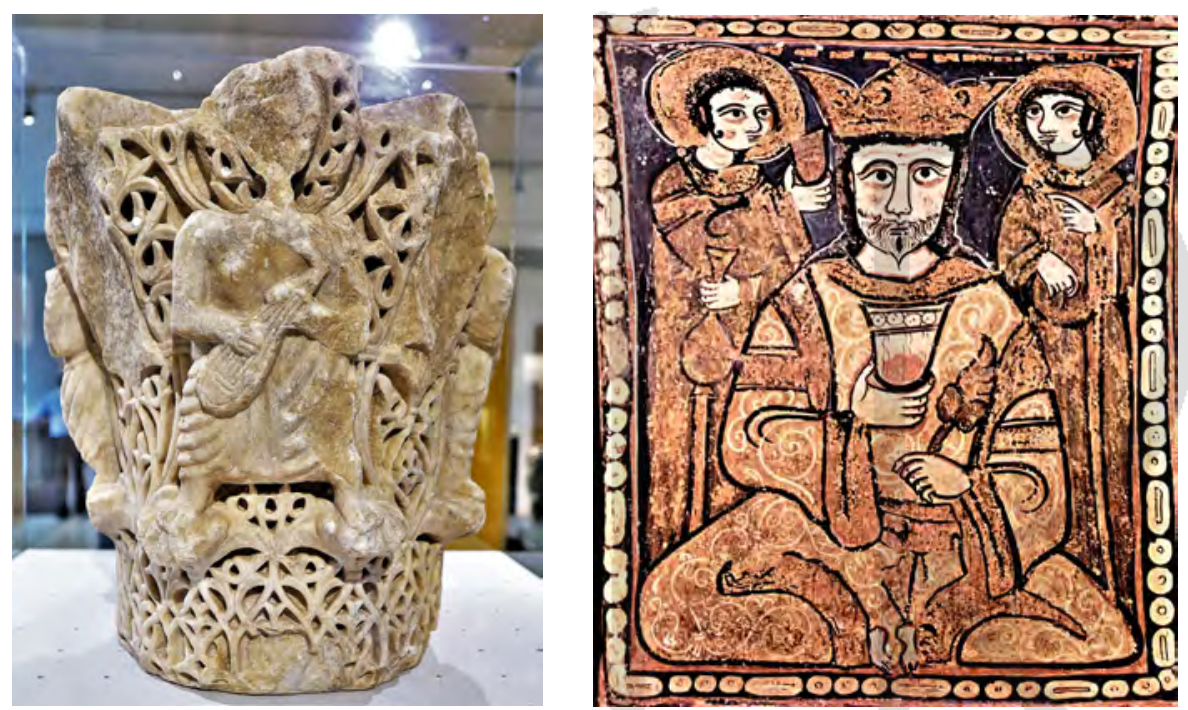

Abb. 10 Figurenkapitell mit Lautenspieler, 10. Jh. Cordoba, Archäologisches Museum. Abb. 11 Der Herrscher in orientalischer Tracht und Sitzhaltung mit dem königlichen Attribut des Bechers wird von seinem Mundschenk und einem/r weiteren Bediensteten flankiert. Während der Herrscher eine stilisierte Flügelkrone trägt, sind die Bediensteten mit einem Nimbus gekennzeichnet. Die islamische Bildsprache kennzeichnet damit keine Heiligen, sondern mit einem Nimbus kann jeder Mensch versehen sein. Demzufolge ist die Bildsprache islamisch, und die Decke der Capella Palatina in Palermo wurde von Handwerkern einer fatimidisch geschulten Werkstatt bemalt. Ob sich der normannische König Roger II. selbst in dieser Pose darstellen ließ, ist durchaus denkbar.

kapitell im Archäologischen Museum von Cordoba aus dem 10. Jahrhundert zu sein (Abb. 10). Wie viele solcher Reliefs oder Plastiken mag es gegeben haben, wo sind die Geschwister der Löwen geblieben, die den berühmten Brunnen im Löwenhof der Alhambra tragen? Immerhin haben sich einige Kleinplastiken in der Funktion von Wasserspendern oder Weihrauchbrennern erhalten. Doch später soll sogar noch von figürlichen Wandmalereien in Murcia ( $\rightarrow$ Abb. 21) und Granada die Rede sein.

Diese schwierige Befundlage in Andalusien mag man damit erklären, dass Vieles während und nach der christlichen Reconquista zerstört wurde oder verloren ging, doch träfe dies nicht für den nordafrikanischen Maghreb zu, der völlig bilderarm erscheint. So ist es doch eher der den Bildern skeptisch gegenüber stehende Islam der berberischen Dynastien Nordafrikas gewesen, der Bilder verhinderte, allen voran die Almohaden, die ihre Spuren nachhaltig auch in Andalusien hinterlassen haben. So bleibt für Andalusien wohl die Erkenntnis, dass eine ursprüngliche Bilderfreude in den folgenden Jahrhunderten versiegte.

\section{Mittelmeerische Elitenkunst (Fatimiden und Mamluken)}

Von der nominell bestehenden Oberhoheit der Abbasiden in Bagdad hatten sich in Nordafrika die Fatimiden faktisch unabhängig gemacht und herrschten dort von 909 bis 1171. Zudem hatten sie ihren Herrschaftsbereich auf Ägypten und Sizilien, zeitweise sogar auf Unteritalien ausgeweitet. Von vergleichsweise wenigen Keramiken ( $\rightarrow$ Abb. 162) oder Holzarbeiten abgesehen, die sich in bzw. aus Ägypten erhalten haben, sind es tatsächlich vor allem vermutlich aus Sizilien stammende Elfenbeinarbeiten, die von der großen Kunstfertigkeit fatimidischer Werkstätten zeugen. Ihre Werke sind auch figürlich gestaltet. Das ikonographische Repertoire umfasst Tiere und Menschen meist als Ausdruck des höfischen Lebens. Wahrscheinlich stammt die Mehrzahl dieser Objekte bereits aus normannischer Zeit, als fatimidische Handwerker und Werkstätten nun unter christlichem Patronat weiter gearbeitet hatten. Einer Textilwerkstatt in Palermo wird der sog. Krönungsmantel Rogers II. zugeschrieben, der später zu den Reichskleinodien gezählt wurde ( $\rightarrow$ Abb. 223a). Diese Beispiele, ihre Verwendung an christlichen Höfen und ihr nachweisbarer Export nach Europa belegen, dass diese Erzeugnisse in fatimidischer Tradition an den weltlichen und geistlichen Höfen des Abendlandes sehr geschätzt waren. Repräsentativ hierfür sind u. a. die sog. Olifanten, geschnitzte Elfenbeinhörner, die aus arabischen bzw. fatimidischen Werkstätten stammen oder in europäischen Werkstätten nach diesen Vorbildern nachgebildet wurden. Olifanten finden sich ausschließlich in abendländischen Schatzkammern oder Museen ( $\rightarrow$ Abb. 37).

In Palermo ist es jedoch vor allem die berühmte Decke in der Capella Palatina, die von fatimidisch geschulten Handwerkern gestaltet wurde. Szenen des typisch islamischen höfischen Repertoirs mit Musikern und Tänzerinnen werden in der Hofkapelle mit christlichen Themen gemischt. Charakteristisch ist das Bild Rogers II. in Gestalt eines arabischen Herrschers im Lotussitz und dem typischen Herrschaftssymbol des Bechers (Abb. 11). Ähnliches gilt für die Malereien an der hölzernen Decke des Domes von Cefalu, die Anlass gaben für eine der umfangreichsten Arbeiten zur islamischen Ikonographie. ${ }^{15}$ So zeugen vor allem die sizilianischen Malereien von einer ausgefeilten Bildkunst der Fatimiden. In Ägypten hingegen ist nur auf den singulären Fund von Malereien in einem Bad in Fustat $(\rightarrow$ Abb. 131) zu verweisen sowie auf einige Fragmente bemalten Papiers, die entweder aus einem illustrierten Manuskript stammen oder einem Handwerker als Vorlage dienten ( $\rightarrow$ Abb. 46).

Die geographische Nähe zum christlichen Abendland hat für die Beliebtheit islamischer Werkstücke an europäischen Höfen gesorgt. Das galt gewiss in gleicher Weise für die Verbreitung mamlukischer Kunstwerke. Vor allem die Metallgefäße der Mamluken, die im 13. Jahrhundert in Ägypten und in der Dschazira herrschten, gelten heute nicht so sehr als islamische Objekte, sondern als Ausdruck einer mittelmeerischen Elitenkunst. Sie waren am Hof des Sultans beliebt, nicht weniger bei den Kreuz-

15 Gelfer-Jørgensen (1986). 

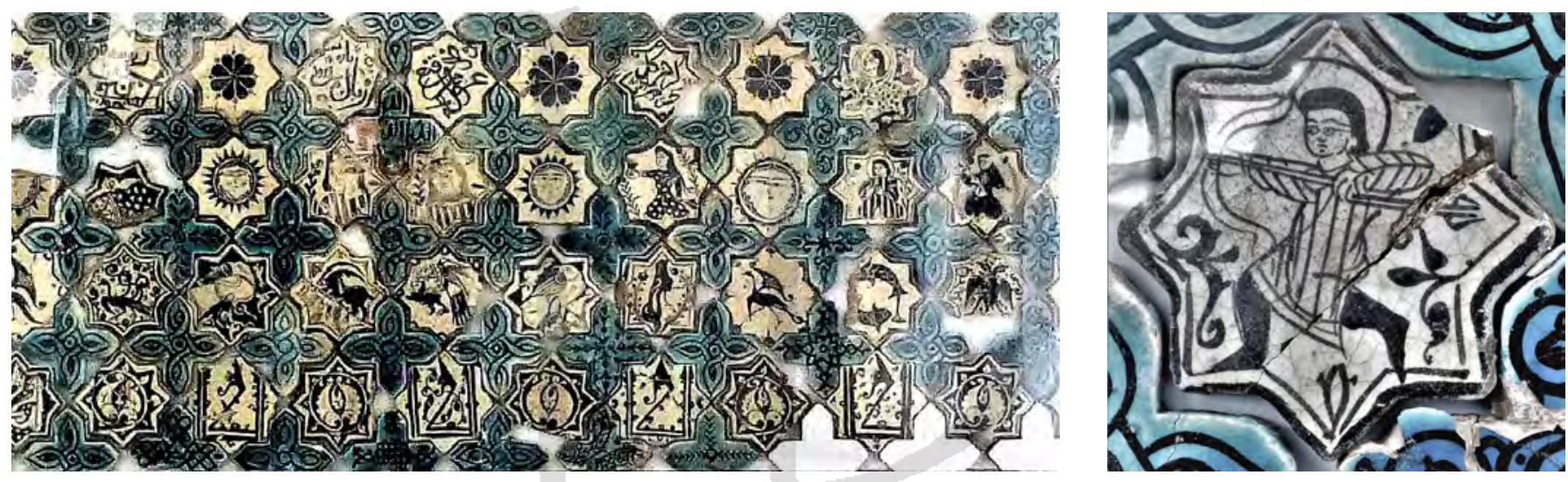

Abb. 12a Flächendeckend waren die Wände im seldschukischen Sommerpalast von Ala ad-Din Kaiqubad I. (1219-1237) in Kubadabad (Anatolien) mit figürlichen Keramiken überzogen. Ob sich aus den Motiven von Ornamenten, Symbolen, Tieren, Fabelwesen und menschlichen Figuren ein Bildprogramm ergibt, sei dahingestellt, aber die Motivik gehört insgesamt ins Repertoire der höfischen Ikonographie. Konya, Karatay Museum. Abb. 12b Das Detail aus der keramischen Wanddekoration im Sommerpalast von Ala ad-Din Kaiqubad I. (1219-1237) in Kubadabad (Anatolien), die sich aus vielen Einzelmotiven zusammensetzt, stellt einen Schützen dar. Dabei kann es sich um einen reitenden Jäger wie um das Sternzeichen Schütze handeln. Konya, Karatay Museum.

fahrern im Heiligen Land, bei den Luisignans auf Zypern ${ }^{16}$ oder sonstwo im christlichen Abendland. Mamlukische Handwerker arbeiteten für den heimischen Markt und den Export ${ }^{17}$ gleichermaßen. Die Objekte sind obwohl Arbeiten islamischer Künstler nicht religiös konnotiert, sondern Zeugnisse der Macht. ${ }^{18}$ So entstand eine kultur- und religionsübergreifende Elitenkunst, die gerade für den europäischen Markt auf Bilder angewiesen war. Freilich stellt sich dann die Frage, ob man es hier mit islamischer Ikonographie zu tun hat; immerhin stammen aber viele Sujets aus dem in der islamischen Kultur so verbreiteten höfischen Szenario. Und die Arbeiten belegen, dass islamische Handwerker nicht mit ihrem Glauben in Konflikt kamen. Ihnen ging es schließlich um Absatz und Verkauf. Solche Objekte werden unter dem Abschnitt ,Kulturgrenzen überschreitende Artefakte im ikonologischen Teil noch behandelt.

\section{Entfaltung der Kunst in Persien und der Jazira (Seldschuken und Zengiden)}

Hinsichtlich der Menge und Vielfalt an figürlichen Darstellungen ist die Epoche der Seldschuken vor allem während ihrer Herrschaft in Persien außerordentlich fruchtbar. Eine wie auch immer geartete Abstinenz gegenüber dem Bild scheint ihnen fremd gewesen zu sein. Die Paläste waren offenkundig mit figürlichen Malereien, Reliefs und Plastiken ausgestattet. ${ }^{19}$ Das legen zumindest

16 Ulrike Ritzerfeld, The Language of Power: Transgressing Borders in Luxury Metal Objects of the Luisignan, in: Sabine Rogge und Michael Grünbart, Hrsg., Medieval Cyprus. A Place of Cultural Encounter, Münster/New York 2015, S. 277-308

17 Rachel Ward, Metallarbeiten der Mamlukenzeit, hergestellt für den Export nach Europa, in: Gereon Sivernich, Hrsg., Europa und der Orient: 8001900, Gütersloh 1989, S. 202-209

18 Robert Ousterhout, Symbole der Macht. Mittelalterliche Heraldik zwischen Ost und West, in: Margit Mersch und Ulrike Ritzerfeld, Hrsg., Lateinisch-griechisch-arabische Begegnungen. Kulturelle Diversität im Mittelmeerraum des Spätmittelalters, Berlin 2009, S. 91-109.

19 Scott Redford, Thirteenth-Century Rum Seljuq Palaces and Palace Imagery, in: Ars Orientalis Vol. 23, Pre-Modern Islamic Palaces (1993), S. 219-236. die Quellen und archäologischen Befunde nahe. Eindrucksvollstes archäologisches Beispiel sind die figürlichen Kacheldekorationen im Sommerpalast von Ala ad-Din Kaiqubad I. (1219-1237) in Kubadabad an den Ufern des Beysehir Sees in Anatolien westlich von Konya. ${ }^{20}$ Sie zeigen eine Vielfalt von Darstellungen des alltäglichen Lebens, von Tieren und Fabelwesen, wie sie einzigartig für das 13. Jahrhundert ist (Abb. 12a). Die sternförmigen Fliesen $(20 \times 24 \mathrm{~cm})$ zeigen alle Arten von Tieren sowie höfische Szenen, darunter Lebensbäume, Sirenen, Sphinxe, Greifen, einoder zweiköpfige Adler, Löwen, Drachen, Pferde, Esel, Pfauen, verschiedene Arten von Wildtieren sowie menschliche Figuren (Abb. 12b). Hier ist nahezu alles versammelt, was in den folgenden Jahrhunderten die islamische Ikonographie beherrscht.

Neben diesem Kompendium figürlicher Darstellungen ist ein großformatiges Relief im Philadelphia Museum of Art $(172 \times 323 \mathrm{~cm})$ bemerkenswert, das in der Gegend von Rayy (Iran) gefunden wurde (Abb. 13a). ${ }^{21}$ Dargestellt ist ein Herrscher mit dem Attribut des Bechers flankiert von seinem Hofpersonal (Abb. 13b); er sitzt auf einem Thron, als dessen Füße kleine Elefanten dienen. Es konnte bis diesem Objekt nicht ausbleiben, dass man sogar seine Echtheit in Zweifel zog. Doch handelt es sich wohl um ein Original, und der thronende Herrscher dürfte mit Tughrul Beg (um 990-1063), dem Begründer der Dynastie zu identifizieren sein. Zumindest bezeichnet ihn die Inschrift am oberen Rand des Reliefs so: „Der Sultan, der König, der Größte, der König Tughrul, der Weise, der Gerechte, der Strenge." Auf dem Thron selbst ist am Rand der Sitzfläche zu lesen: „Der König, triumphierend, gerecht".

Erhalten haben sich weiterhin Portraitköpfe, in denen man wohl seldschukische Prinzen sehen darf ( $\rightarrow$ Abb. 271b). Das Relief und die Portraitköpfe lassen bereits erkennen, dass die Ikonographie dieser Epoche um die Dynastie und das höfische

20 Rüçhan Arık, Kubad Abad. Selçuklu Saray ve Çinileri, Istanbul 2000.

21 Sheila R. Canby u.a., Court and Cosmos. The Great Age of the Seljuqs, Metropolitan Museum of Art, New York 2016, Kat. Nr. 16. 

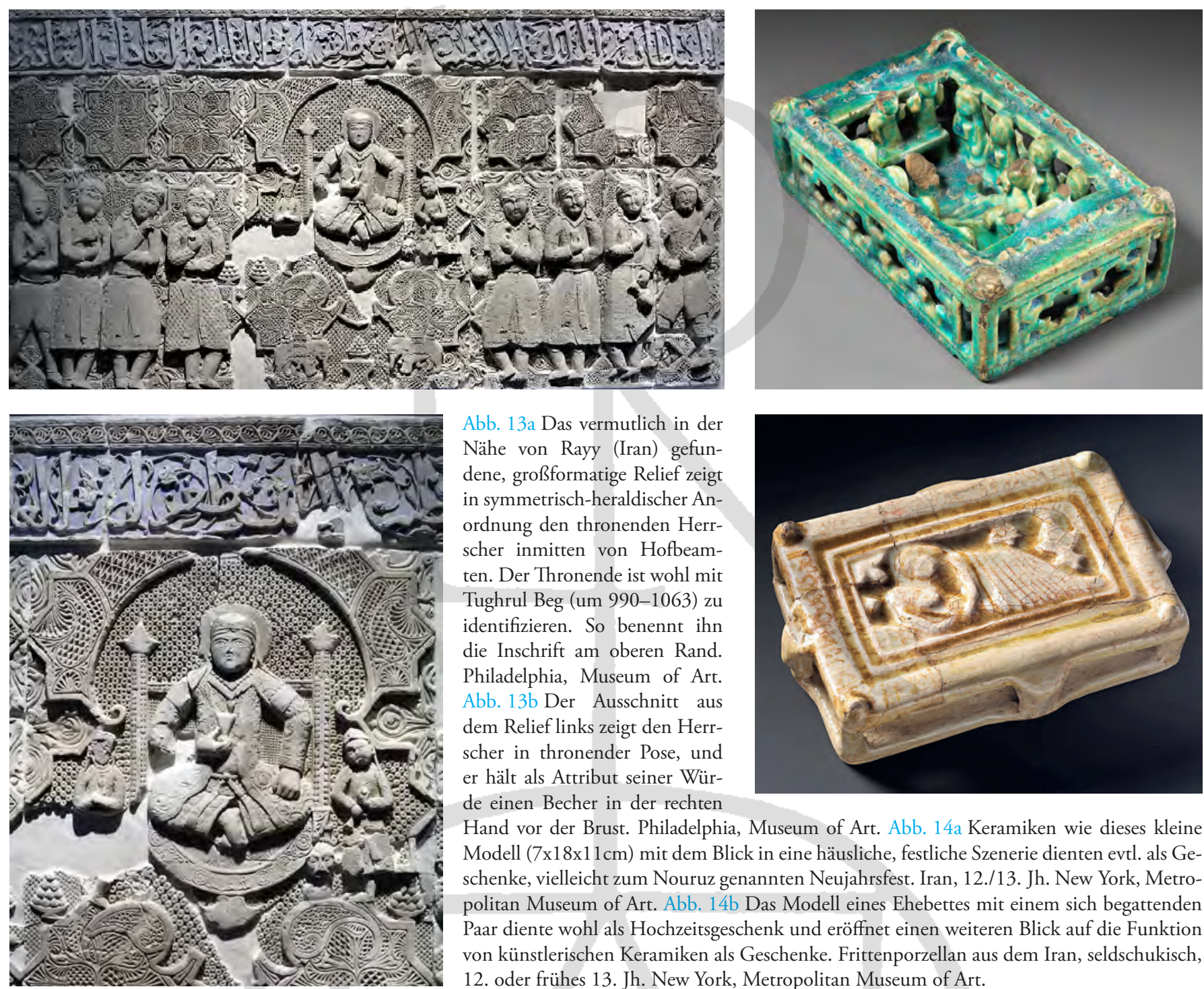

Abb. 13a Das vermutlich in der Nähe von Rayy (Iran) gefundene, großformatige Relief zeigt in symmetrisch-heraldischer Anordnung den thronenden Herrscher inmitten von Hofbeamten. Der Thronende ist wohl mit Tughrul Beg (um 990-1063) zu identifizieren. So benennt ihn die Inschrift am oberen Rand. Philadelphia, Museum of Art. Abb. 13b Der Ausschnitt aus dem Relief links zeigt den Herrscher in thronender Pose, und er hält als Attribut seiner Wür-

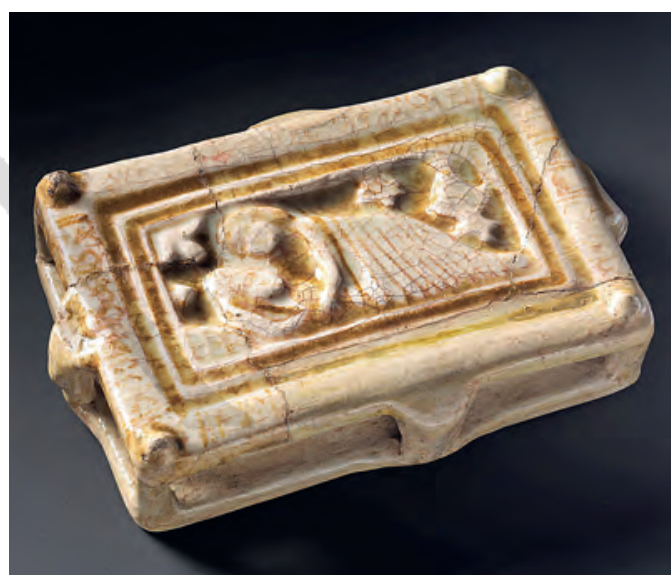
de einen Becher in der rechten

Hand vor der Brust. Philadelphia, Museum of Art. Abb. 14a Keramiken wie dieses kleine Modell $(7 \times 18 \times 11 \mathrm{~cm})$ mit dem Blick in eine häusliche, festliche Szenerie dienten evtl. als Geschenke, vielleicht zum Nouruz genannten Neujahrsfest. Iran, 12./13. Jh. New York, Metropolitan Museum of Art. Abb. 14b Das Modell eines Ehebettes mit einem sich begattenden Paar diente wohl als Hochzeitsgeschenk und eröffnet einen weiteren Blick auf die Funktion von künstlerischen Keramiken als Geschenke. Frittenporzellan aus dem Iran, seldschukisch, 12. oder frühes 13. Jh. New York, Metropolitan Museum of Art.

Leben kreist. So zeigen die Objekte der Kleinkunst mit Tanz und Musik, mit Spiel und festlichem Gelage alle fürstlichen Privilegien und Lustbarkeiten. Zu den Symbolen der Macht gehören zudem die Fabelwesen, die sich für ihren opulenten Auftritt in der islamischen Bildwelt rüsten. Gewissenhaft nutzte man die Astrologie als Ratgeber für die Politik und das Leben.

Unter den zahlreichen figürlich dekorierten Keramiken fällt eine kleine Gruppe von modellhaften Objekten ins Auge, die den Blick in das Innere eines Hauses eröffnen, in dem offenkundig ein Fest gefeiert wird. Es darf angenommen werden, dass es sich dabei um Geschenke für solche festlichen Anlässe, vielleicht das Nouruz Fest handelt (Abb. 14a). Als Hochzeitsgeschenk diente möglicherweise das modellhaft dargestellte Ehebett mit einem Paar während des Beischlafs (Abb. 14b).

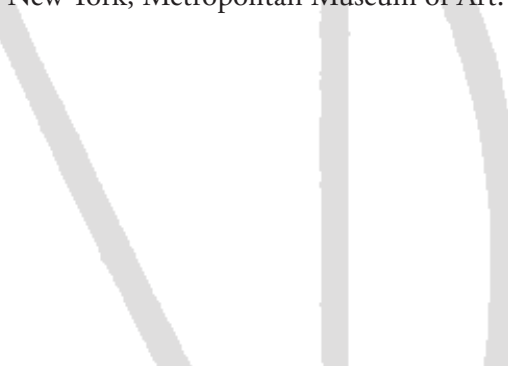

Geschenke sind überhaupt das Thema, wenn man nach dem Verwendungszweck aufwändig dekorierter Schalen und Gefäße fragt. Wahrscheinlich können hier einige besonders exquisite Metallarbeiten des 12./13. Jahrhunderts eingeordnet werden, deren Werkstätten und teils namentlich bekannte Handwerker nach Mossul (Nordirak) bzw. nach Syrien lokalisiert werden. Mit ihrem Dekor gehören sie dem Umfeld höfischen Lebens an. Herausragende Exemplare sind die sog. Blacas-Kanne $(\rightarrow \text { Abb. 44, 173b })^{22}$ und die Vaso Vescovali ${ }^{23}$. Sie enthalten das gesamte höfische Repertoire einschließlich der astronomischen Zeichen für Planeten und den Zodiakus. Besonders auffallend erscheint jedoch die Tatsache, dass sich auf manchen Objekten die höfischen Szenen mit eindeutig christlicher Thematik mi-

22 Ebd., Kat. Nr. 15.

23 Ebd., Kat. Nr. 124. 